\title{
Fuzzy Least-Squares Linear Regression Approach to Ascertain Stochastic Demand in the Vehicle Routing Problem
}

\author{
Fatemeh Torfi $^{1,2}$, Reza Zanjirani Farahani ${ }^{3}$, Iraj Mahdavi ${ }^{1}$ \\ ${ }^{1}$ Department of Industrial Engineering, Islamic Azad University, Semnan Branch, Semnan, Iran \\ ${ }^{2}$ Department of Industrial Engineering, Mazandaran University of Science and Technology, Babol, Iran \\ ${ }^{3}$ Department of Industrial Engineering, Amirkabir University of Technology, Tehran, Iran \\ E-mail: irajarash@rediffmail.com,f_torfi2000@yahoo.com \\ Received September 5, 2010; revised November 13, 2010; accepted November 17, 2010
}

\begin{abstract}
Estimation of stochastic demand in physical distribution in general and efficient transport routs management in particular is emerging as a crucial factor in urban planning domain. It is particularly important in some municipalities such as Tehran where a sound demand management calls for a realistic analysis of the routing system. The methodology involved critically investigating a fuzzy least-squares linear regression approach $\left(\mathrm{FLLR}_{\mathrm{s}}\right)$ to estimate the stochastic demands in the vehicle routing problem (VRP) bearing in mind the customer's preferences order. A FLLR method is proposed in solving the VRP with stochastic demands: approximate-distance fuzzy least-squares (ADFL) estimator ADFL estimator is applied to original data taken from a case study. The SSR values of the ADFL estimator and real demand are obtained and then compared to SSR values of the nominal demand and real demand. Empirical results showed that the proposed method can be viable in solving problems under circumstances of having vague and imprecise performance ratings. The results further proved that application of the ADFL was realistic and efficient estimator to face the stochastic demand challenges in vehicle routing system management and solve relevant problems.
\end{abstract}

Keywords: Fuzzy Least-Squares, Stochastic, Location, Routing Problems

\section{Introduction}

The problem within distribution management of scheduling vehicles from one or more fixed positions (depots) to service a given set of locations (customers) is called the vehicle routing problem (VRP) [1]. Vehicle routing problems are important and well-known combinatorial optimization problems occurring in many transport logistics and distribution systems of considerable economic significance vehicle routing problem with stochastic demand (VRPSD) has recently received a lot of attention in the literature [2]. This is mainly because of the wide applicability of stochastic demand in real-world cases. In the routing problem with stochastic demands (RPSD) a vehicle has to serve a set of customers whose exact demand is known only upon arrival at the customer's location. The objective in these problems is to find a permutation of the customer's demands that the penalties for losing a customer are minimized [3]. The actual demand of each customer depends on common assumptions on mathematical programming where all problem data are known in advance. In most cases, however, decisions have to be made before the realizations of random variables are known. A classical approach is to work with estimations of random data and to solve the stochastic problem similar to the deterministic cases. Moreover, it is often preferable to explicitly incorporate uncertainty in the models. Fuzzy Theory is a powerful tool, for decision making in fuzzy environment. Crisp methods work only with exact and ordinary data, so there is no place for fuzzy and vagueness data. Torfi et al. [4] proposed a Fuzzy approach to evaluate the alternative options in respect to the user's preference orders in a fuzzy environment. Human has a good ability for qualitative data processing, which helps him or her to make decisions in fuzzy environment. In many practical cases, decisions are uncertain and they are reluctant or unable to make numerical input and output data. Torfi et al. [5] applied a 
new fuzzy decision making model to determine the weights of multiple objectives in combinational optimization problems.

In this paper, we apply their basic approximation operations in fuzzy least-squares estimator. This paper considers a stochastic routing problem in which a set of customers is given, each of which will require service after the a priori decision is made. Uncertainty is modeled by using a vector of dependent variables which are intervallic and similar to the demand vector. Each of these in turn depends on independent variables which are also intervallic. However, in many practical cases, the customer's demands are uncertain and those who demand service are reluctant or unable to make a numerical permutation of the customer's demands. Fuzzy least squares linear regression was assumed to be a powerful tool for decision-making in fuzzy environment. Fuzzy regression analysis is a fuzzy (or possibility) type of classical regression analysis. It is applied under circumstances where evaluation of the functional relationship between the dependent and independent variables in a fuzzy environment is necessary.

Tanaka et al. [6] initiated a study in fuzzy linear regression analysis that considered the parameter estimation of models as linear programming problems. Based on the findings of Tanaka et al., further investigations were made, which took two approaches: the linear-programming-based methods [6-9] and fuzzy least-squares methods [10-12]. Most of these fuzzy regression models are analytically considered with fuzzy outputs and fuzzy parameters but non-fuzzy (crisp) inputs. This paper aims to study fuzzy linear regression model with fuzzy outputs, fuzzy parameters, and fuzzy inputs.

Sakawa and Yano [9] proposed a fuzzy parameter estimation model for the fuzzy linear regression (FLR) model as follows:

$$
Y_{i}=A_{0}+A_{1} X_{j 1}+\cdots+A_{k} X_{j k}, j=1,2, \cdots, n .
$$

Where both input data $\mathrm{X}_{\mathrm{j} 1}, \mathrm{X}_{\mathrm{j} 2}, \cdots, \mathrm{X}_{\mathrm{jk}}$ and output data $Y_{j}$ are fuzzy. Three types of multi-objective programming problems were further formulated for the parameter estimation of FLR models along with a linear-programming-based approach. This multicriterial analysis of FLR models provided an appropriate method of parameter estimation by using the vagueness of the model via some indices of inclusion relations. Alternatively, a fuzzy least-squares approach directly uses information included in the input-output data set and considers the measure of best fitting based on distance under fuzzy consideration.

Fuzzy least-squares are fuzzy extensions of ordinary least-squares. In this paper, one type of fuzzy leastsquares is proposed as the parameter estimation for the FLR model is proposed as follows:

$$
Y_{i}=A_{0}+A_{1} X_{j 1}+\cdots+A_{k} X_{j k}, j=1,2, \cdots, n .
$$

Yang and Lin [1] used two approaches to evaluate the functional relationship between the dependent and independent variables in a fuzzy environment. Their analyticcal framework involved fuzzy linear regression models with fuzzy outputs, fuzzy inputs, and fuzzy parameters, but the fuzzy numbers they considered in their model were of LR-type.

In this paper, attempt is made to apply an extension of one of their approaches with triangular fuzzy numbers. The proposed methodology presents the extension of approximate-distance fuzzy least-squares (ADFL) estimator. The proposed method is assumed to be appropriate alternative approach to estimate the stochastic demands in the routing problem.

The remainder of this paper is outlined as follows: Sections 2 introduce the method used to compute the stochastic demands. Then, the routing problem with stochastic demands is presented in Section 3. Section 4 presents the results of computational experiments to assess the value of the proposed approach and reports a comparative performance analysis to alternate method. Finally, in Section 5 conclusions and future researches are drawn.

\section{Fuzzy Least-Squares Linear Regression}

The rationale for the Fuzzy Theory is briefly reviewed before developing fuzzy Least-squares Linear Regression as follows:

\subsection{Fuzzy Arithmetic}

Definition 2.1. A Fuzzy set $M$ in a universe of discourse $X$ is characterized by a membership function $\mu_{M}(x)$ which associates with each element $x$ in $X$, a real number in the interval [0,1]. The function value $\mu_{M}(x)$ is termed the grade of membership of $x$ in M [13]. The present study uses triangular Fuzzy numbers. A triangular Fuzzy number, $\mathrm{M}$, can be defined by a triplet $M=(\alpha, \beta, \delta)_{T}$. Its conceptual schema and mathematical form are shown by Equation (1).

$$
\mu_{\tilde{a}}(x)=\left\{\begin{array}{cc}
0 & x \leq \alpha \\
\frac{x-\alpha}{\beta-\alpha} & \alpha \prec x \leq \beta \\
\frac{\delta-x}{\delta-\beta} & \beta \prec x \leq \delta \\
1 & x \succ \delta
\end{array}\right.
$$

Definition 2.2. Let $M=(\alpha, \beta, \delta)_{T}$ and $N=(\chi, \gamma, \lambda)_{T}$ be two triangular Fuzzy numbers, then the vertex method is defined to calculate the distance between them, as Eq- 
uation (2):

$$
d_{T}^{2}(X, Y)=\left(\alpha_{x}-\alpha_{y}\right)^{2}+\left(\beta_{x}-\beta_{y}\right)^{2}+\left(\delta_{x}-\delta_{y}\right)^{2}
$$

The basic operations on Fuzzy triangular numbers are as follows [14]:

For approximation of multiplication [15]:

$$
(\alpha, \beta, \delta)_{T} \times(\chi, \gamma, \lambda)_{T} \cong(\alpha \times \chi, \beta \times \gamma, \delta \times \lambda)_{T}
$$

For addition:

$$
(\alpha, \beta, \delta)_{T}+(\chi, \gamma, \lambda)_{T} \cong(\alpha+\chi, \beta+\gamma, \delta+\lambda)_{T}
$$

Given the above-mentioned Fuzzy theory, the proposed Fuzzy Least-squares Linear Regression Approach is then defined as follows:

\subsection{Developed Version of the Approximate-Distance Fuzzy Least-Squares}

This is basically an extension of and improvement on the model applied by Yang and Lin [16] above which is expressed by the FLR model as follows:

$$
(F L R): Y_{i}=A_{0}+A_{1} X_{j 1}+\cdots+A_{k} X_{j k}, j=1,2, \cdots, n,
$$

Where outputs $Y_{j}=\left(\alpha_{Y_{j}}, \beta_{Y_{j}}, \delta_{Y_{j}}\right)_{T}$, inputs

$$
X_{j i}=\left(\alpha_{X_{j i}}, \beta_{X_{j i}}, \delta_{X_{j i}}\right)_{T} \text { and parameters }
$$

$A_{j}=\left(\alpha_{a_{j}}, \beta_{a_{j}}, \delta_{a_{j}}\right)_{T} \forall i=1,2, \cdots, k, j=1,2, \cdots, n$ so that the notion $M=(\alpha, \beta, \delta)_{T}$ is triangular fuzzy number.

The difficulty in treating model (5) of fuzzy inputoutput data is that $\mathrm{A}_{\mathrm{i}} \mathrm{X}_{\mathrm{ji}}$ may not be of triangular fuzzy number. Although the product of two triangular fuzzy numbers may not be a triangular fuzzy number, Dubois and Prade [17] presented an approximation form. Based on this analytical framework, Yang and Ko [11] further developed the model presented by Dubois and Prade and suggested an approximation type of fuzzy least-squares. What follows here is the application of approximation to present an algorithm for parameter estimation of the FLR model (5).

By assuming $M=(\alpha, \beta, \delta)_{T}$ and $N=(\chi, \gamma, \lambda)_{T}$ to be two triangular Fuzzy numbers; therefore, by using the basic operations on Fuzzy triangular numbers, it will be possible to express an approximation of multiplication and addition as follows:

where

$$
A_{0}+A_{1} X_{j 1}+\cdots+A_{k} X_{j k} \cong\left(\tilde{\alpha}_{j}, \tilde{\beta}_{j}, \tilde{\delta}_{j}\right)_{T}
$$

$$
\begin{aligned}
& \tilde{\alpha}_{j}=\tilde{\alpha}_{a_{0}}+\sum_{p=1}^{k}\left(\tilde{\alpha}_{a_{p}} * \tilde{\alpha}_{x_{j p}}\right) \\
& \tilde{\beta}_{j}=\tilde{\beta}_{a_{0}}+\sum_{p=1}^{k}\left(\tilde{\beta}_{a_{p}} * \tilde{\beta}_{x_{j p}}\right) \\
& \tilde{\delta}_{j}=\tilde{\delta}_{a_{0}}+\sum_{p=1}^{k}\left(\tilde{\delta}_{a_{p}} * \tilde{\delta}_{x_{j p}}\right)
\end{aligned}
$$

Since $A_{0}+A_{1} X_{j 1}+\cdots+A_{k} X_{j k}$ is of approximate triangular fuzzy number, the distance $d_{T}^{2}$ is defined on two triangular fuzzy numbers. Thus, the following object- tive function is considered:

$$
\begin{aligned}
& U\left(A_{0}, A_{1}, \ldots, A_{k}\right)=\sum_{j=1}^{n} d_{T}^{2}\left(Y_{j}, A_{0}+A_{1} X_{j 1}+\cdots+A_{k} X_{j k}\right) \\
& =\sum_{j=1}^{n} \frac{1}{3}\left[\left(\alpha_{y_{j}}-\tilde{\alpha}_{j}\right)^{2}+\left(\beta_{y_{j}}-\tilde{\beta}_{j}\right)^{2}+\left(\delta_{y_{j}}-\tilde{\delta}_{j}\right)^{2}\right]
\end{aligned}
$$

The minimization of $U\left(A_{0}, A_{1}, \cdots, A_{k}\right)$ over $A_{i}$ subject to $0 \leq \alpha_{a_{i}} 1,0 \leq \beta_{a_{i}} \leq 1,0 \leq \delta_{a_{i}} \leq 1, \quad i=0,1,2, \cdots, k \quad$ is called the developed version of the approximate-distance fuzzy least-squares method.

\subsection{Fuzzy Membership Function}

The existing precise values is deliberately transformed here to five levels ranking order of Fuzzy linguistic variables: very low $(\mathrm{VL})$, low $(\mathrm{L})$, medium $(\mathrm{M})$, high $(\mathrm{H})$ and very high (VH). The commonly used Fuzzy numbers applied for the triangular fuzzy numbers are likely to be appropriate for the trapezoidal ones due to their simplicity in modeling interpretations. Both triangular and trapezoidal fuzzy numbers are applicable to the present study. The triangular fuzzy number applied here can adequately present an analytical framework within sevenlevel Fuzzy linguistic variables, for the present study. These linguistic variables can be expressed in triangular numbers as Tables 1 and 2 [3].

Table 1. Linguistic variables for the importance weight of each criterion.

\begin{tabular}{ccc}
\hline Rank & Criteria grade & Membership function \\
\hline Very low (VL) & 1 & $(0.00,0.10,0.25)$ \\
Low (L) & 2 & $(0.15,0.30,0.45)$ \\
Medium (M) & 3 & $(0.35,0.50,0.65)$ \\
High (H) & 4 & $(0.55,0.70,0.85)$ \\
Very high (VH) & 5 & $(0.75,0.90,1.00)$ \\
\hline
\end{tabular}

Table 2. Linguistic variables for the ratings.

\begin{tabular}{ccc}
\hline Rank & Criteria grade & Membership function \\
\hline Very poor (VP) & 1 & $(0,1,2.5)$ \\
Poor (P) & 2 & $(1.5,3,4.5)$ \\
Medium (MP) & 3 & $(3.5,5,6.5)$ \\
Good (G) & 4 & $(5.5,7,8.5)$ \\
Very good (VG) & 5 & $(7.5,9,10)$ \\
\hline
\end{tabular}




\section{Statement of the Problem}

In this stochastic routing problem, capacities on the plants are given in terms of number of customers whom each plant can actually serve, and the capacity of vehicles employed to provide services are available.

The aim of this study is to allocate customers to the plants in question. It is assumed that there are circumstances when a plant is overloaded, (i.e., the number of customers on its route requesting service exceeds its capacity), and a number of customers are left without service, which incur an additional costs to the plant. This additional cost can be interpreted as the penalty for losing a customer, or as the cost of acquiring external resources to provide the service. Here, the demand made by the set of customer, which the plant has to satisfy, is stochastic. The stochastic nature of the demand is a good reason to take the fuzzy approach. The demand made by each node is a function of factors such as the demand time, age of the vehicles employed, quality improvement of product and distance of a particular node to the plant, etc.

The goal in this RPSD is to minimize the penalty for losing a customer, defined as the sum of the expected penalties incurred for the customers who did not receive service. The uncertainty in demand is modeled by using a vector of dependent variables, which in turn the linear combination of the dependent variables generates independent variables. However, in many practical cases, the customer's demands are uncertain and they are reluctant or unable to make a numerical permutation of the customer's demands. Fuzzy least squares liner regression is a powerful tool for decision making in fuzzy environments. Fuzzy regression analysis is a fuzzy (or possibility) type of classical regression analysis. It is used in evaluating the functional relationship between the dependent and independent variables in a fuzzy environ- ment.

This paper uses estimation method along with a fuzzy least-squares approach, which can be effectively used to estimate the customer demand. The outcomes of the method are compared for problem solution. A fuzzy regression model is used in evaluating the functional relationship between the dependent and independent variables in a fuzzy environment. Most fuzzy regression models are considered fuzzy outputs and parameters but non-fuzzy (crisp) inputs. In general, there are two approaches in the analysis of fuzzy regression models: linear-programming based on fuzzy least-square methods. Sakawa and Yano [9] considered fuzzy linear regression models with fuzzy outputs, fuzzy parameters and fuzzy inputs. They formulated multi-objective programming methods for the model estimation along with a linearprogramming-based approach.

\section{Procedure Experiment}

In Sections 2, a fuzzy least-squares method has been constructed for the estimation of a routing problem with stochastic demands and fuzzy input-output data.

Given the above-mentioned approach, the procedure experiment is then defined as follows:

Step 1 . The first step for constructing the linear regression model involved collection of available data about the problems to be solved. For the purpose of this study, the most important and effective factors, which are perceived by the experts to influence the demand made by a particular node, will be determined.

Since the influencing factors in this study were merely the perceptions of the stakeholders involved, and as such, are considered as qualitative data (i.e., conditions of quality improvement of product). This renders the data subjective, as different experts view the world reality from their own perspective. This in turn depends on their experience and professional qualifications. Four of the most effective factors for estimating the demand made by a specific node can be seen in Table 3 .

Step 2. The second step involved measuring the real demand for the 90 nodes in a single period of one year. The following factors were taken into consideration:

These factors, as independent variables, are used in the model to estimate the demand made by each node. For example, $X_{2}$ is the variable for quality improvement of product, which consists of four evaluative categories like in line with the Likkert scale model, which comprises good, average, rather poor and poor. Very high VH, average $H$, rather poor $M$ and poor $L$, symbolize the good emulative category. These are also used for other independent variables and the results are shown in Table 4.

Step 3. Functional objectives and the constraints associated with the model used in this study are calculated from the method provided in 2.2, which make mathematical programming problem and model parameters, which are triangular fuzzy numbers, are the answer to these problems. Numerical results of the problem under investigation using the Mathematica and Lingo8 software, which include coefficients of variables of the

Table 3. Effective factors for estimating the demand.

\begin{tabular}{|c|c|c|}
\hline NO & CRITERIA & STATUS \\
\hline 1 & $\begin{array}{l}\text { Distance of the plant to } \\
\text { particular node }\end{array}$ & $\begin{array}{l}\text { Less than 5, Between 5 10, } \\
\text { More than } 10\end{array}$ \\
\hline 2 & $\begin{array}{l}\text { Quality improvement of } \\
\text { product }\end{array}$ & $\begin{array}{l}\text { Good-Average-Rather } \\
\text { poor-Poor }\end{array}$ \\
\hline 3 & Demand time & Spring-summer-autumn-winter \\
\hline 4 & $\begin{array}{l}\text { Age of the vehicles em- } \\
\text { ployed }\end{array}$ & $\begin{array}{l}\text { Less than } 5 \text {, Between } 5 \sim 10 \text {, } \\
\text { More than } 10\end{array}$ \\
\hline
\end{tabular}


Table 4. Results of real demand for the 90 nodes.

\begin{tabular}{|c|c|c|c|c|c|c|c|c|c|c|c|c|c|c|c|c|c|}
\hline \multirow{2}{*}{$\begin{array}{c}\text { variable } \\
\text { node }\end{array}$} & \multirow{2}{*}{1} & \multirow[b]{2}{*}{2} & \multirow[b]{2}{*}{3} & \multirow[b]{2}{*}{4} & \multirow[b]{2}{*}{5} & \multirow{2}{*}{$\begin{array}{c}\text { variable } \\
\text { node }\end{array}$} & \multirow[b]{2}{*}{1} & \multirow[b]{2}{*}{2} & \multirow[b]{2}{*}{3} & \multirow[b]{2}{*}{4} & \multirow[b]{2}{*}{5} & \multirow{2}{*}{$\begin{array}{c}\text { variable } \\
\text { node }\end{array}$} & \multirow[b]{2}{*}{1} & \multirow[b]{2}{*}{2} & \multirow[b]{2}{*}{3} & \multirow[b]{2}{*}{4} & \multirow[b]{2}{*}{5} \\
\hline & & & & & & & & & & & & & & & & & \\
\hline 1 & $\mathrm{~L}$ & $\mathrm{M}$ & M & $\mathrm{H}$ & $\mathrm{VH}$ & 31 & $\mathrm{H}$ & $\mathrm{VH}$ & $\mathrm{M}$ & $\mathrm{H}$ & VH & 61 & L & VH & $\mathrm{M}$ & $\mathrm{VH}$ & $\mathrm{VH}$ \\
\hline 2 & $\mathrm{~L}$ & $\mathrm{M}$ & M & $\mathrm{VH}$ & $\mathrm{H}$ & 32 & $\mathrm{~L}$ & $\mathrm{M}$ & $\mathrm{H}$ & $\mathrm{VH}$ & VH & 62 & $\mathrm{~L}$ & M & $\mathrm{M}$ & $\mathrm{VH}$ & $\mathrm{H}$ \\
\hline 3 & $\mathrm{~L}$ & VH & M & VH & $\mathrm{VH}$ & 33 & M & $\mathrm{VH}$ & $\mathrm{M}$ & $\mathrm{VH}$ & VH & 63 & $\mathrm{H}$ & $\mathrm{H}$ & $\mathrm{H}$ & $\mathrm{VH}$ & $\mathrm{H}$ \\
\hline 4 & $\mathrm{~L}$ & $\mathrm{M}$ & $\mathrm{H}$ & $\mathrm{VH}$ & $\mathrm{M}$ & 34 & M & VH & $\mathrm{H}$ & $\mathrm{H}$ & $\mathrm{H}$ & 64 & $\mathrm{M}$ & VH & $\mathrm{H}$ & $\mathrm{VH}$ & $\mathrm{VH}$ \\
\hline 5 & $\mathrm{M}$ & $\mathrm{H}$ & M & $\mathrm{H}$ & $\mathrm{H}$ & 35 & $\mathrm{VH}$ & $\mathrm{H}$ & $\mathrm{M}$ & $\mathrm{VH}$ & VH & 65 & $\mathrm{~L}$ & M & $\mathrm{M}$ & $\mathrm{H}$ & $\mathrm{VH}$ \\
\hline 6 & $\mathrm{~L}$ & $\mathrm{VH}$ & $\mathrm{L}$ & M & $\mathrm{H}$ & 36 & $\mathrm{~L}$ & $\mathrm{H}$ & $\mathrm{H}$ & M & $\mathrm{H}$ & 66 & $\mathrm{VH}$ & VH & $\mathrm{M}$ & $\mathrm{L}$ & $\mathrm{H}$ \\
\hline 7 & $\mathrm{M}$ & $\mathrm{H}$ & $\mathrm{VH}$ & $\mathrm{H}$ & $\mathrm{H}$ & 37 & $\mathrm{~L}$ & $\mathrm{H}$ & $\mathrm{H}$ & $\mathrm{H}$ & $\mathrm{VH}$ & 67 & $\mathrm{M}$ & $\mathrm{H}$ & $\mathrm{M}$ & $\mathrm{M}$ & $\mathrm{VH}$ \\
\hline 8 & $\mathrm{H}$ & $\mathrm{H}$ & M & $\mathrm{L}$ & $\mathrm{H}$ & 38 & $\mathrm{~L}$ & $\mathrm{~L}$ & $\mathrm{M}$ & $\mathrm{VH}$ & $\mathrm{H}$ & 68 & $\mathrm{VH}$ & VH & $\mathrm{M}$ & $\mathrm{H}$ & $\mathrm{H}$ \\
\hline 9 & $\mathrm{~L}$ & $\mathrm{H}$ & $\mathrm{H}$ & $\mathrm{VH}$ & $\mathrm{VH}$ & 39 & $\mathrm{~L}$ & $\mathrm{M}$ & $\mathrm{H}$ & $\mathrm{H}$ & VH & 69 & $\mathrm{M}$ & $\mathrm{H}$ & $\mathrm{H}$ & $\mathrm{VH}$ & $\mathrm{H}$ \\
\hline 10 & $\mathrm{~L}$ & $\mathrm{M}$ & $\mathrm{H}$ & $\mathrm{H}$ & $\mathrm{H}$ & 40 & $\mathrm{~L}$ & VH & $\mathrm{H}$ & $\mathrm{H}$ & $\mathrm{VH}$ & 70 & $\mathrm{~L}$ & VH & $\mathrm{M}$ & $\mathrm{H}$ & $\mathrm{H}$ \\
\hline 11 & $\mathrm{M}$ & $\mathrm{H}$ & M & $\mathrm{H}$ & $\mathrm{H}$ & 41 & $\mathrm{~L}$ & $\mathrm{H}$ & $\mathrm{H}$ & $\mathrm{H}$ & $\mathrm{H}$ & 71 & $\mathrm{~L}$ & M & $\mathrm{H}$ & $\mathrm{VH}$ & $\mathrm{VH}$ \\
\hline 12 & $\mathrm{~L}$ & L & $\mathrm{H}$ & $\mathrm{VH}$ & $\mathrm{H}$ & 42 & VL & M & $\mathrm{H}$ & $\mathrm{VH}$ & $\mathrm{H}$ & 72 & $\mathrm{VH}$ & VH & $\mathrm{H}$ & $\mathrm{H}$ & $\mathrm{H}$ \\
\hline 13 & $\mathrm{~L}$ & $\mathrm{H}$ & $\mathrm{H}$ & $\mathrm{H}$ & $\mathrm{VH}$ & 43 & $\mathrm{M}$ & $\mathrm{H}$ & $\mathrm{M}$ & M & $\mathrm{H}$ & 73 & $\mathrm{~L}$ & $\mathrm{M}$ & $\mathrm{H}$ & $\mathrm{VH}$ & $\mathrm{H}$ \\
\hline 14 & $\mathrm{~L}$ & $\mathrm{H}$ & $\mathrm{H}$ & $\mathrm{VH}$ & $\mathrm{VH}$ & 44 & M & $\mathrm{M}$ & $\mathrm{M}$ & $\mathrm{H}$ & $\mathrm{H}$ & 74 & $\mathrm{VH}$ & $\mathrm{H}$ & $\mathrm{M}$ & $\mathrm{H}$ & $\mathrm{VH}$ \\
\hline 15 & $\mathrm{M}$ & $\mathrm{H}$ & $\mathrm{M}$ & $\mathrm{H}$ & $\mathrm{H}$ & 45 & $\mathrm{~L}$ & $\mathrm{H}$ & VH & $\mathrm{H}$ & $\mathrm{H}$ & 75 & $\mathrm{M}$ & $\mathrm{VH}$ & $\mathrm{H}$ & $\mathrm{H}$ & $\mathrm{VH}$ \\
\hline 16 & $\mathrm{~L}$ & $\mathrm{VH}$ & $\mathrm{H}$ & $\mathrm{H}$ & $\mathrm{H}$ & 46 & M & $\mathrm{H}$ & $\mathrm{H}$ & $\mathrm{VH}$ & VH & 76 & $\mathrm{~L}$ & $\mathrm{H}$ & $\mathrm{M}$ & $\mathrm{H}$ & $\mathrm{H}$ \\
\hline 17 & $\mathrm{H}$ & $\mathrm{H}$ & $\mathrm{H}$ & $\mathrm{VH}$ & $\mathrm{H}$ & 47 & $\mathrm{~L}$ & $\mathrm{VH}$ & $\mathrm{M}$ & $\mathrm{L}$ & $\mathrm{VH}$ & 77 & $\mathrm{~L}$ & VH & $\mathrm{H}$ & $\mathrm{VH}$ & $\mathrm{VH}$ \\
\hline 18 & $\mathrm{M}$ & $\mathrm{H}$ & $\mathrm{VH}$ & $\mathrm{H}$ & $\mathrm{VH}$ & 48 & M & $\mathrm{H}$ & VH & $\mathrm{H}$ & VH & 78 & L & $\mathrm{H}$ & $\mathrm{M}$ & $\mathrm{VH}$ & $\mathrm{H}$ \\
\hline 19 & $\mathrm{~L}$ & $\mathrm{VH}$ & $\mathrm{H}$ & $\mathrm{VH}$ & $\mathrm{VH}$ & 49 & M & M & $\mathrm{M}$ & VH & $\mathrm{VH}$ & 79 & M & VH & $\mathrm{H}$ & $\mathrm{VH}$ & $\mathrm{H}$ \\
\hline 20 & $\mathrm{~L}$ & $\mathrm{H}$ & $\mathrm{M}$ & VL & $\mathrm{VH}$ & 50 & $\mathrm{H}$ & $\mathrm{H}$ & VH & $\mathrm{VH}$ & $\mathrm{H}$ & 80 & $\mathrm{~L}$ & $\mathrm{VH}$ & $\mathrm{H}$ & $\mathrm{H}$ & $\mathrm{VH}$ \\
\hline 21 & VL & $\mathrm{M}$ & $\mathrm{H}$ & VH & $\mathrm{H}$ & 51 & VL & $\mathrm{VH}$ & $\mathrm{H}$ & $\mathrm{VH}$ & $\mathrm{VH}$ & 81 & $\mathrm{~L}$ & $\mathrm{H}$ & $\mathrm{M}$ & $\mathrm{M}$ & $\mathrm{H}$ \\
\hline 22 & $\mathrm{M}$ & $\mathrm{H}$ & $\mathrm{M}$ & $\mathrm{H}$ & $\mathrm{H}$ & 52 & $\mathrm{~L}$ & $\mathrm{H}$ & $\mathrm{H}$ & $\mathrm{VH}$ & $\mathrm{H}$ & 82 & $\mathrm{~L}$ & $\mathrm{H}$ & $\mathrm{H}$ & $\mathrm{VH}$ & $\mathrm{VH}$ \\
\hline 23 & $\mathrm{~L}$ & L & $\mathrm{H}$ & VH & $\mathrm{H}$ & 53 & VL & M & $\mathrm{H}$ & $\mathrm{VH}$ & $\mathrm{H}$ & 83 & $\mathrm{VH}$ & $\mathrm{H}$ & $\mathrm{M}$ & $\mathrm{H}$ & $\mathrm{H}$ \\
\hline 24 & VL & $\mathrm{H}$ & $\mathrm{H}$ & $\mathrm{VH}$ & $\mathrm{VH}$ & 54 & M & $\mathrm{H}$ & $\mathrm{M}$ & M & $\mathrm{H}$ & 84 & M & $\mathrm{H}$ & $\mathrm{M}$ & $\mathrm{VH}$ & $\mathrm{H}$ \\
\hline 25 & $\mathrm{~L}$ & $\mathrm{VH}$ & $\mathrm{M}$ & $\mathrm{VH}$ & $\mathrm{VH}$ & 55 & M & M & $\mathrm{H}$ & VH & $\mathrm{H}$ & 85 & $\mathrm{VH}$ & $\mathrm{H}$ & $\mathrm{L}$ & $\mathrm{H}$ & $\mathrm{VH}$ \\
\hline 26 & $\mathrm{M}$ & $\mathrm{H}$ & $\mathrm{M}$ & VH & $\mathrm{H}$ & 56 & $\mathrm{~L}$ & $\mathrm{H}$ & $\mathrm{H}$ & $\mathrm{H}$ & $\mathrm{H}$ & 86 & M & VH & $\mathrm{M}$ & $\mathrm{H}$ & $\mathrm{VH}$ \\
\hline 27 & $\mathrm{~L}$ & $\mathrm{VH}$ & $\mathrm{M}$ & $\mathrm{H}$ & $\mathrm{VH}$ & 57 & $\mathrm{M}$ & $\mathrm{H}$ & $\mathrm{M}$ & $\mathrm{H}$ & $\mathrm{VH}$ & 87 & $\mathrm{~L}$ & $\mathrm{H}$ & $\mathrm{M}$ & $\mathrm{H}$ & $\mathrm{H}$ \\
\hline 28 & $\mathrm{H}$ & $\mathrm{VH}$ & $\mathrm{H}$ & VH & $\mathrm{H}$ & 58 & $\mathrm{~L}$ & $\mathrm{VH}$ & $\mathrm{M}$ & $\mathrm{L}$ & $\mathrm{VH}$ & 88 & $\mathrm{M}$ & $\mathrm{VH}$ & $\mathrm{M}$ & $\mathrm{VH}$ & $\mathrm{VH}$ \\
\hline 29 & $\mathrm{M}$ & $\mathrm{H}$ & $\mathrm{M}$ & $\mathrm{H}$ & $\mathrm{VH}$ & 59 & M & $\mathrm{H}$ & $\mathrm{M}$ & $\mathrm{H}$ & VH & 89 & $\mathrm{~L}$ & $\mathrm{H}$ & $\mathrm{M}$ & $\mathrm{VH}$ & $\mathrm{H}$ \\
\hline 30 & $\mathrm{M}$ & VH & $\mathrm{H}$ & VH & $\mathrm{VH}$ & 60 & M & M & $\mathrm{M}$ & VH & VH & 90 & $\mathrm{M}$ & VH & $\mathrm{M}$ & $\mathrm{VH}$ & $\mathrm{H}$ \\
\hline
\end{tabular}


Table 5. Parameter estimates and SSR for model 1.

\begin{tabular}{|c|c|c|c|c|c|c|c|}
\hline \multirow{2}{*}{ No. } & \multicolumn{3}{|c|}{ Apprximate- distance $(\tilde{Y})$} & \multirow{2}{*}{$\begin{array}{l}\text { Nominal demand } \\
\qquad(\hat{Y})\end{array}$} & \multirow{2}{*}{$\begin{array}{l}\text { Real demand } \\
\qquad(Y)\end{array}$} & \multirow{2}{*}{$\begin{array}{l}\text { SSR based on Apprximate- } \\
\text { distance } d_{T}^{2}(Y, \tilde{Y})\end{array}$} & \multirow{2}{*}{$d_{T}^{2}(Y, \hat{Y})$} \\
\hline & $\tilde{\alpha}_{y}$ & $\tilde{\beta}_{y}$ & $\tilde{\delta}_{y}$ & & & & \\
\hline & 0.00 & 0.10 & 0.25 & $\mathbf{H}$ & $\mathbf{L}$ & 0.320156 & 0.692820 \\
\hline 2 & 0.00 & 0.10 & 0.25 & $\mathbf{L}$ & $\mathbf{L}$ & 0.320156 & $\mathbf{0}$ \\
\hline 3 & 0.15 & 0.3 & 045 & $\mathbf{L}$ & $\mathbf{M}$ & 0.346410 & 0.346410 \\
\hline 4 & 0.00 & 0.10 & 0.25 & $\mathbf{L}$ & $\mathbf{L}$ & 0.320156 & $\mathbf{0}$ \\
\hline 5 & 0.00 & 0.10 & 0.25 & $\mathbf{L}$ & $\mathbf{L}$ & 0.320156 & $\mathbf{0}$ \\
\hline 6 & 0.35 & 0.5 & 0.65 & $\mathbf{L}$ & $\mathbf{M}$ & $\mathbf{0}$ & 0.346410 \\
\hline 7 & 0.00 & 0.10 & 0.25 & $\mathbf{L}$ & $\mathbf{L}$ & 0.320156 & $\mathbf{0}$ \\
\hline 8 & 0.00 & 0.10 & 0.25 & $\mathbf{L}$ & $\mathbf{L}$ & 0.320156 & $\mathbf{0}$ \\
\hline 9 & 0.35 & 0.5 & 0.65 & $\mathbf{L}$ & $\mathbf{H}$ & 0.346410 & 0.692820 \\
\hline 10 & 0.15 & 0.3 & 045 & $\mathbf{L}$ & $\mathbf{L}$ & $\mathbf{0}$ & $\mathbf{0}$ \\
\hline 11 & 0.00 & 0.10 & 0.25 & $\mathbf{L}$ & $\mathbf{L}$ & 0.320156 & 0 \\
\hline 12 & 0.15 & 0.3 & 045 & $\mathbf{L}$ & $\mathbf{L}$ & $\mathbf{0}$ & 0 \\
\hline 13 & 0.15 & 0.3 & 045 & $\mathbf{L}$ & $\mathbf{M}$ & 0 & 0.346410 \\
\hline 14 & 0.00 & 0.10 & 0.25 & $\mathbf{L}$ & $\mathbf{L}$ & 0.320156 & 0 \\
\hline 15 & 0.35 & 0.5 & 0.65 & M & $\mathbf{H}$ & 0.346410 & 0.346410 \\
\hline 16 & 0.00 & 0.10 & 0.25 & $\mathbf{L}$ & $\mathbf{L}$ & 0.320156 & 0 \\
\hline 17 & 0.00 & 0.10 & 0.25 & $\mathbf{M}$ & VL & 0 & 0.665206 \\
\hline 18 & 0.00 & 0.10 & 0.25 & $\mathbf{L}$ & $\mathbf{L}$ & 0.320156 & 0 \\
\hline 19 & 0.35 & 0.5 & 0.65 & VH & M & 0 & 0.665206 \\
\hline 20 & 0.15 & 0.3 & 045 & $\mathbf{L}$ & $\mathbf{L}$ & 0 & 0 \\
\hline 21 & 0.00 & 0.10 & 0.25 & $\mathbf{L}$ & $\mathbf{L}$ & 0.320156 & 0 \\
\hline 22 & 0.15 & 0.3 & 045 & $\mathbf{L}$ & $\mathbf{L}$ & 0 & 0 \\
\hline 23 & 0.35 & 0.5 & 0.65 & $\mathbf{H}$ & $\mathbf{H}$ & 0.346410 & 0 \\
\hline 24 & 0.00 & 0.10 & 0.25 & $\mathbf{L}$ & $\mathbf{L}$ & 0.320156 & 0 \\
\hline 25 & 0.35 & 0.5 & 0.65 & VH & $\mathbf{H}$ & 0.346410 & 0.320156 \\
\hline 26 & 0.15 & 0.3 & 045 & $\mathbf{L}$ & $\mathbf{L}$ & 0 & 0 \\
\hline 27 & 0.15 & 0.3 & 045 & $\mathbf{L}$ & $\mathbf{L}$ & 0 & 0 \\
\hline 28 & 0.00 & 0.10 & 0.25 & VL & $\mathbf{L}$ & 0.346410 & 0.665206 \\
\hline 29 & 0.00 & 0.10 & 0.25 & $\mathbf{L}$ & $\mathbf{L}$ & 0.346410 & $\mathbf{0}$ \\
\hline 30 & 0.15 & 0.3 & 045 & VL & $\mathbf{M}$ & 0.665206 & 0.665206 \\
\hline 31 & 0.35 & 0.5 & 0.65 & $\mathbf{L}$ & $\mathbf{M}$ & 0 & 0.346410 \\
\hline 32 & 0.00 & 0.10 & 0.25 & VL & $\mathbf{L}$ & 0.320156 & 0.320156 \\
\hline 33 & 0.35 & 0.5 & 0.65 & $\mathbf{M}$ & $\mathbf{M}$ & 0 & 0 \\
\hline 34 & 0.00 & 0.10 & 0.25 & $\mathbf{H}$ & $\mathbf{M}$ & 0.136667 & 0.346410 \\
\hline
\end{tabular}




\begin{tabular}{|c|c|c|c|c|c|c|c|}
\hline 35 & 0.15 & 0.3 & 045 & $\mathbf{L}$ & $\mathbf{L}$ & $\mathbf{0}$ & $\mathbf{0}$ \\
\hline 36 & 0.35 & 0.5 & 0.65 & $\mathbf{L}$ & $\mathbf{H}$ & 0.346410 & 0.692820 \\
\hline 37 & 0.00 & 0.10 & 0.25 & VL & $\mathbf{L}$ & 0.320156 & 0.320156 \\
\hline 38 & 0.15 & 0.3 & 045 & $\mathbf{L}$ & $\mathbf{L}$ & 0 & 0 \\
\hline 39 & 0.00 & 0.10 & 0.25 & $\mathbf{L}$ & $\mathbf{L}$ & 0.320156 & $\mathbf{0}$ \\
\hline 40 & 0.15 & 0.3 & 045 & $\mathbf{L}$ & $\mathbf{L}$ & 0 & $\mathbf{0}$ \\
\hline 41 & 0.15 & 0.3 & 045 & VL & $\mathbf{L}$ & 0 & 0.320156 \\
\hline 42 & 0.15 & 0.3 & 045 & $\mathbf{L}$ & $\mathbf{L}$ & $\mathbf{0}$ & $\mathbf{0}$ \\
\hline 43 & 0.35 & 0.5 & 0.65 & $\mathbf{L}$ & $\mathbf{M}$ & 0 & 0.346410 \\
\hline 44 & 0.35 & 0.5 & 0.65 & $\mathbf{L}$ & $\mathbf{L}$ & 0.346410 & $\mathbf{0}$ \\
\hline 45 & 0.15 & 0.3 & 045 & $\mathbf{L}$ & $\mathbf{L}$ & 0 & 0 \\
\hline 46 & 0.15 & 0.3 & 045 & VL & $\mathbf{L}$ & 0 & 0.320156 \\
\hline 47 & 0.35 & 0.5 & 0.65 & $\mathbf{L}$ & $\mathbf{H}$ & 0.346410 & 0.692820 \\
\hline 48 & 0.00 & 0.10 & 0.25 & $\mathbf{L}$ & $\mathbf{L}$ & 0.320156 & $\mathbf{0}$ \\
\hline 49 & 0.15 & 0.3 & 045 & $\mathbf{L}$ & $\mathbf{L}$ & 0 & 0 \\
\hline 50 & 0.35 & 0.5 & 0.65 & VL & $\mathbf{H}$ & 0.346410 & 1.011187 \\
\hline 51 & 0.00 & 0.10 & 0.25 & $\mathbf{L}$ & $\mathbf{L}$ & 0.320156 & $\mathbf{0}$ \\
\hline 52 & 0.35 & 0.5 & 0.65 & $\mathbf{M}$ & $\mathbf{H}$ & 0.346410 & 0.346410 \\
\hline 53 & 0.75 & 0.9 & 1.00 & $\mathbf{M}$ & VH & 0 & 0.665206 \\
\hline 54 & 0.00 & 0.10 & 0.25 & $\mathbf{L}$ & $\mathbf{L}$ & 0.320156 & $\mathbf{0}$ \\
\hline 55 & 0.15 & 0.3 & 045 & $\mathbf{L}$ & $\mathbf{L}$ & 0 & 0 \\
\hline 56 & 0.15 & 0.3 & 045 & $\mathbf{L}$ & $\mathbf{L}$ & $\mathbf{0}$ & $\mathbf{0}$ \\
\hline 57 & 0.75 & 0.9 & 1.00 & $\mathbf{M}$ & $\mathbf{H}$ & 0.320156 & 0.346410 \\
\hline 58 & 0.15 & 0.3 & 045 & $\mathbf{L}$ & $\mathbf{L}$ & 0 & 0 \\
\hline 59 & 0.55 & 0.7 & 0.85 & $\mathbf{L}$ & $\mathbf{M}$ & 0.346410 & 0.346410 \\
\hline 60 & 0.15 & 0.3 & 045 & $\mathbf{M}$ & $\mathbf{L}$ & 0 & 0.346410 \\
\hline 61 & 0.35 & 0.5 & 0.65 & $\mathbf{H}$ & $\mathbf{M}$ & 0 & 0.346410 \\
\hline 62 & 0.00 & 0.10 & 0.25 & $\mathbf{L}$ & $\mathbf{L}$ & 0.320156 & $\mathbf{0}$ \\
\hline 63 & 0.15 & 0.3 & 045 & $\mathbf{L}$ & $\mathbf{M}$ & 0.346410 & 0.346410 \\
\hline 64 & 0.15 & 0.3 & 045 & $\mathbf{L}$ & $\mathbf{L}$ & 0 & 0 \\
\hline 65 & 0.15 & 0.3 & 045 & $\mathbf{L}$ & $\mathbf{L}$ & 0 & 0 \\
\hline 66 & 0.35 & 0.5 & 0.65 & $\mathbf{M}$ & $\mathbf{H}$ & 0.346410 & 0.346410 \\
\hline 67 & 0.00 & 0.10 & 0.25 & $\mathbf{L}$ & $\mathbf{L}$ & 0.320156 & $\mathbf{0}$ \\
\hline 68 & 0.15 & 0.3 & 045 & $\mathbf{L}$ & $\mathbf{L}$ & 0 & 0 \\
\hline 69 & 0.35 & 0.5 & 0.65 & $\mathbf{L}$ & $\mathbf{H}$ & 0.346410 & 0.692820 \\
\hline 70 & 0.15 & 0.3 & 045 & $\mathbf{L}$ & $\mathbf{L}$ & $\mathbf{0}$ & $\mathbf{0}$ \\
\hline
\end{tabular}




\begin{tabular}{|c|c|c|c|c|c|c|c|}
\hline 71 & 0.15 & 0.3 & 045 & $\mathbf{L}$ & $\mathbf{L}$ & 0 & 0 \\
\hline 72 & 0.15 & 0.3 & 045 & $\mathbf{L}$ & $\mathbf{L}$ & 0 & 0 \\
\hline 73 & 0.15 & 0.3 & 045 & $\mathbf{L}$ & $\mathbf{M}$ & 0.346410 & 0.346410 \\
\hline 74 & 0.00 & 0.10 & 0.25 & L & $\mathbf{L}$ & 0.320156 & $\mathbf{0}$ \\
\hline 75 & 0.35 & 0.5 & 0.65 & $\mathbf{M}$ & $\mathbf{H}$ & 0.346410 & 0.346410 \\
\hline 76 & 0.15 & 0.3 & 045 & $\mathbf{L}$ & $\mathbf{L}$ & 0 & 0 \\
\hline 77 & 0.35 & 0.5 & 0.65 & $\mathbf{M}$ & $\mathbf{L}$ & 0.346410 & 0.346410 \\
\hline 78 & 0.00 & 0.10 & 0.25 & $\mathbf{L}$ & $\mathbf{L}$ & 0.320156 & $\mathbf{0}$ \\
\hline 79 & 0.35 & 0.5 & 0.65 & VH & $\mathbf{M}$ & 0 & 0.665206 \\
\hline 80 & 0.00 & 0.10 & 0.25 & $\mathbf{L}$ & $\mathbf{L}$ & 0.320156 & $\mathbf{0}$ \\
\hline 81 & 0.15 & 0.3 & 045 & $\mathbf{L}$ & $\mathbf{L}$ & 0 & 0 \\
\hline 82 & 0.15 & 0.3 & 045 & $\mathbf{L}$ & $\mathbf{L}$ & 0 & 0 \\
\hline 83 & 0.35 & 0.5 & 0.65 & $\mathbf{H}$ & $\mathbf{H}$ & 0.346410 & $\mathbf{0}$ \\
\hline 84 & 0.00 & 0.10 & 0.25 & $\mathbf{L}$ & $\mathbf{L}$ & 0.320156 & $\mathbf{0}$ \\
\hline 85 & 0.35 & 0.5 & 0.65 & VH & $\mathbf{H}$ & 0.346410 & 0.320156 \\
\hline 86 & 0.00 & 0.10 & 0.25 & $\mathbf{L}$ & $\mathbf{L}$ & 0.320156 & $\mathbf{0}$ \\
\hline 87 & 0.15 & 0.3 & 045 & $\mathbf{L}$ & $\mathbf{L}$ & 0 & 0 \\
\hline 88 & 0.15 & 0.3 & 045 & VL & $\mathbf{L}$ & 0 & 0.320156 \\
\hline 89 & 0.15 & 0.3 & 045 & $\mathbf{L}$ & $\mathbf{L}$ & $\mathbf{0}$ & 0 \\
\hline 90 & 0.15 & 0.3 & 045 & VL & $\mathbf{M}$ & 0 & 0.665206 \\
\hline \multicolumn{6}{|c|}{ SUM } & 16.40054 & 17.26179 \\
\hline
\end{tabular}

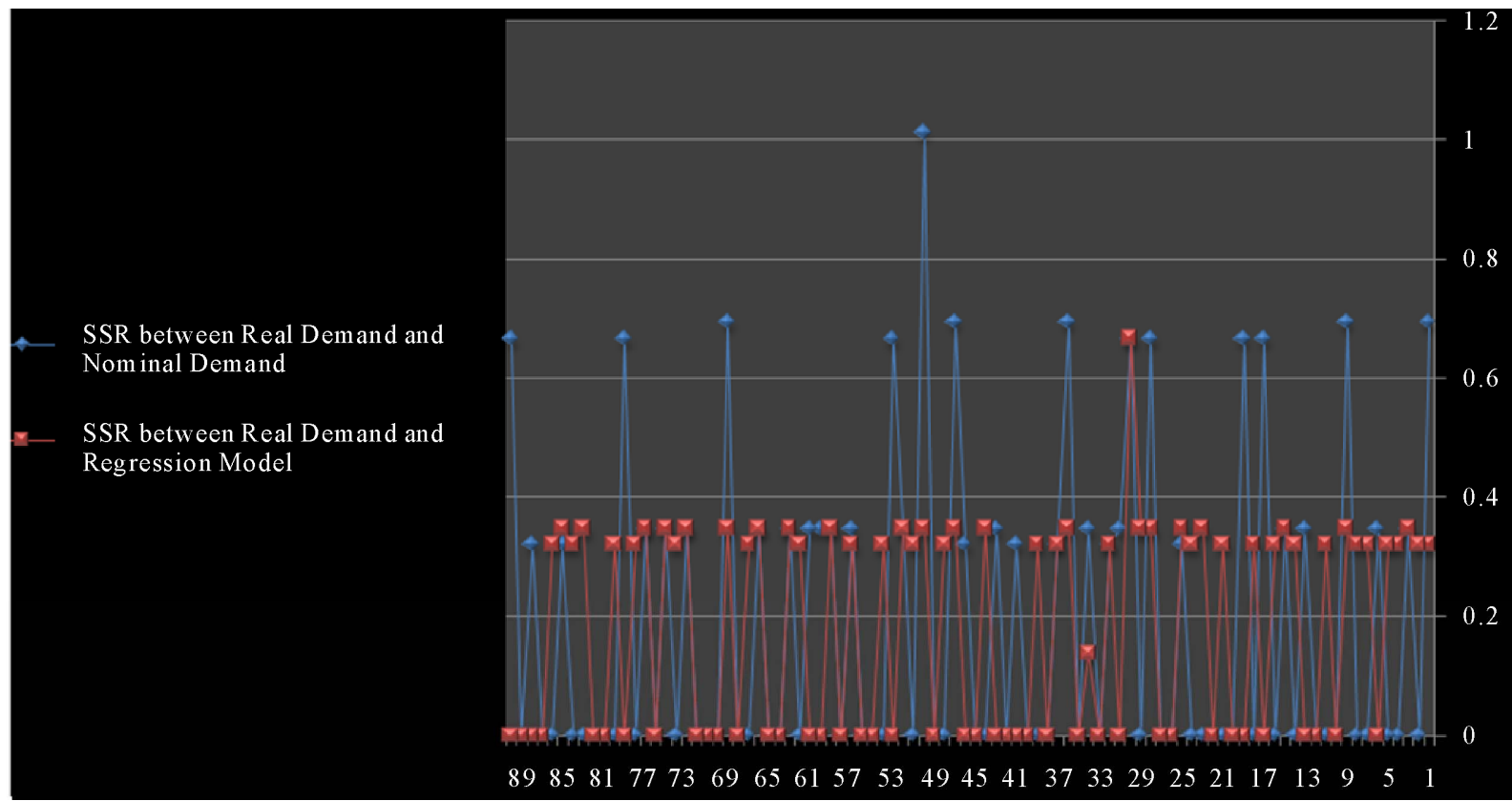

Figure 1. SSR between actual demand and regression model, with real demand and nominal demand. 
model based on the algorithm. Therefore the presented regression model calculated the demands of each node.

Step 4. Simultaneously with the measurements of the real 90 nodes, the nominal demands were calculated from the company's' documents and data.

Step 5. Calculate SSR based on Apprximate-distance and Real demand and SSR based on Nominal demand and Real demand by Equation (2) and the result of step 3 and step 4 are shown in Tables 5.

The results in Table 5 show that the $\mathrm{SSR}_{\mathrm{s}}$ based on the distance $d_{T}^{2}(Y, \tilde{Y})$ and $d_{T}^{2}(Y, \hat{Y})$. Based on this Table, the last step found the preference for the company's' documents and Approximate-distance approach as follows:

$$
d_{T}^{2}(Y, \tilde{Y})<d_{T}^{2}(Y, \hat{Y})
$$

\section{Computational Results}

The demands derived from the Approximate-distance method, are similar to the results obtained from real demand. The results of approximate-distance fuzzy least-squares also substantiated the results of real environment, whereas the $\mathrm{SSR}_{\mathrm{s}}$ in the Approximate-distance method $\left(d_{T}^{2}(Y, \tilde{Y})\right)$ less than $\mathrm{SSR}_{\mathrm{s}}$ in the Nominal demand $\left(d_{T}^{2}(Y, \hat{Y})\right)$. Results suggest that the application of the fuzzy systematic evaluation in the estimation problems can reduce the risk in decision-making processes.

Comparison regression model and the real demand, with real demand and nominal demand, are shown in Figure 1.

\section{Conclusions}

The paper aimed at a critical analysis of estimation method to address the demand management in transport routing system. For this purpose the methodology involved proposing a developed version of the intervalistance, fuzzy least square as a realistic approach in addressing and solving the problem. Results indicated that the use of the fuzzy logic proved a much closer solution to the real-world situation than its comparative methods. Results further showed that the method which was applied here yielded better solution to the problem than was possible from the data on demand obtained from the company documents. It was further observed that under certain cases where the three crucial components of inputs, outputs and parameters are somewhat vague and stochastic, the fuzzy linear regression is a more powerful analytical tool and as such, would be more preferable than others. The conclusion being that it would be more viable to apply trapezium fuzzy numbers as an analytical framework for industrial case studies.

\section{References}

[1] R. J. Petch and S. Salhi, "A Multi-Phase Constructive Heuristic for the Vehicle Routing Problem with Multiple Trips,” Discrete Applied Mathematics, Vol. 133, No. 1-3, 2004, pp. 69-92. doi:10.1016/S0166-218X(03)00434-7

[2] D. Mester and O. Braysy, “Active Guided Evolution Strategies for Large-Scale Vehicle Routing Problems with Time Windows," Computers and Operations Research, Vol. 32, No. 6, 2005, pp. 1593-1614. doi:10.1016/j.cor. 2003.11.017

[3] A. S. Maria, F. Elena and L. Gilbert, "Heuristic and Lower Bound for a Stochastic Location-Routing Problem,” European Journal of Operational Research, Vol. 179, No. 3, 2007, pp. 940-955. doi:10.1016/j.ejor.2005. 04.051

[4] F. Torfi, R. Z. Farahani and S. Rezapour, "Fuzzy AHP to Determine the Relative Weights of Evaluation Criteria and Fuzzy TOPSIS to Rank the Alternatives" Applied Soft Computing, Vol. 10, No. 2, 2010, pp. 520-528. doi: 10.1016/j.asoc.2009.08.021

[5] F. Torfi, R. Z. Farahani and N. Hedayat, “A New Model to Determine the Weights of Multiple Objectives in Combinational Optimization Problems," Proceedings of ICCESSE International Conference on Computer, Electrical, Systems Science and Engineering, 07, Paris, 2010, pp. 1933-1955.

[6] H. Tanaka, S. Vegima and K. Asai, "Linear Regression Analysis with Fuzzy Model,” IEEE Transactions on Systems, Man, and Cybernet, Vol. 12, No. 6, 1982, pp. 903-907.

[7] H. Tanaka and H. Ishibuchi, "Identification of Positivistic Linear Systems by Quadratic Membership Functions of Fuzzy Parameters,” Fuzzy Sets and Systems, Vol. 41, 1991, pp. 145-160. doi:10.1016/0165-0114(91)90218-F

[8] H. Tanaka, H. Ishibuchi and S.Yoshikawa, "Exponential Possibility Regression Analysis,” Fuzzy Sets and Systems, Vol. 69, No. 3, 1995, pp. 305-318. doi:10.1016/01650114(94)00179-B

[9] M. Sakawa and H. Yano, "Multiobjective Fuzzy Linear Regression Analysis for Fuzzy Input-Output Data,” Fuzzy Sets and Systems, Vol. 47, 1992, pp. 173-181. doi: 10.1016/0165-0114(92)90175-4

[10] M. Albrecht, “Approximation of Functional Relationships to Fuzzy Observations,” Fuzzy Sets and Systems, Vol. 49, No. 3, 1992, pp. 301-305. doi:10.1016/0165-0114(92) 90281-8

[11] M. S. Yang and C.H. Ko, "On Cluster-Wise Fuzzy Regression Analysis,” IEEE Transactions on Systems, Man, and Cybernet, Vol. 27, No. 1, 1997, pp. 1-13. doi: 10.1109/3477.552181

[12] P. Diamond, "Fuzzy Least Squares,” Information Science, Vol. 46, 1988, pp. 141-157. doi:10.1016/0020-0255(88) 90047-3 
[13] L. A. Zadeh, "Fuzzy Sets,” Information Control, Vol. 8, 1965, pp. 338-53. doi:10.1016/S0019-9958(65)90241-X

[14] T. Yang and H. Chih-Ching, "Multiple-Attribute Decision Making Methods for Plant Layout Design Problem,” Robotics and computer-integrated manufacturing, Vol. 23, No. 1, 2007, pp. 126-137. doi:10.1016/j.rcim.2005. 12.002

[15] C. T. Chen, "Extensions of the TOPSIS for Group Decision-Making under Fuzzy Environment," Fuzzy Sets and
Systems, Vol. 114, No. 1, 2000, pp. 1-9. doi:10.1016/ S0165-0114(97)00377-1

[16] M. S. Yang and T. S. Lin, "Fuzzy Least-Squares Linear Regression Analysis for Fuzzy Input-Output Data,” Fuzzy Sets and Systems, Vol. 126, No. 3, 2002, pp. 389-399. doi:10.1016/S0165-0114(01)00066-5

[17] D. Dubois and H. Prade, "Fuzzy Sets and Systems: Theory and Applications,” Academic Press, New York, 1980 . 